demonstrates that some high income countries have unreliable statistics and some low-income countries are able set up good data collection systems. Therefore, all countries should be able to set up reasonable data reporting systems given the right policies. Vulnerable road user fatalities constitute the majority of all road traffic injury fatalities in all large Asian countries including the high income countries. Overall and road user specific death rates do not have a high correlation with income levels. The reasons for this are not known. It appears that factors other than income levels, car and road design and policing influence death rates per-capita for each country. Much more work will have to be done in this area before the variability in crash rates can be explained satisfactorily for Asian countries. In the absence of more reliable data and identification of risk factors for each country, it is not possible to give very specific country based countermeasures for road safety. It would be adequate at present to focus on measures that have international validity and are known not to have negative side-effects. There are wide variations in crash patterns within countries of similar income. The reasons for these variations need to be investigated on an urgent basis.

\title{
0070 STATUS OF ROAD TRAFFIC INJURIES IN ASIA
}

D Mohan* Correspondence: Indian Institute of Technology Delhi, TRIPP, Room 808 Main Bldng Hauz Khas New Delhi 110016, India

\subsection{6/ip.2010.029215.70}

The WHO released a Global Status Report On Road Safety: Time For Action in July 2009. This report is the first broad assessment of the status of road safety in 178 countries. Here we analyse the data reported by Asian countries. The report 